\title{
VARIABILIDADE ESPACIAL DOS TEORES FOLIARES DE NUTRIENTES E DA PRODUTIVIDADE DA SOJA EM DOIS ANOS DE CULTIVO EM UM LATOSSOLO VERMELHO(1)
}

\author{
Sidney Rosa Vieira ${ }^{(2)}$, Osvaldo Guedes Filho ${ }^{(3)}$, Márcio Koiti Chiba ${ }^{(2)}$, Estevão \\ Vicari Mellis $^{(2)}$, Sônia Carmela Falci Dechen ${ }^{(2)} \&$ Isabella Clerici De Maria $^{(2)}$
}

\begin{abstract}
RESUMO
A análise dos teores de nutrientes de folhas de soja é um dos métodos mais eficientes para avaliar o estado nutricional da lavoura. O objetivo deste estudo foi caracterizar a variabilidade espacial dos teores foliares de nutrientes e da produtividade da cultura da soja num Latossolo Vermelho sob sistema semeadura direta durante dois anos. A área do experimento media $120 \times 160 \mathrm{~m}$, totalizando 1,92 ha. As amostras de folhas e os dados de produtividade da soja foram coletados em grade regular de $20 \mathrm{~m}$, totalizando 63 pontos de amostragem nos anos de $1986 \mathrm{e}$ 1988. O teor de nutrientes (N, P, K, Ca, Mg, S, B, Cu, Fe, Mn e Zn) foi determinado analisando-se a terceira folha com pecíolo a partir do ápice de cinco plantas, em locais circunvizinhos de cada um dos pontos de amostragem. As produtividades de soja foram quantificadas em subparcelas de $5 \mathrm{~m}^{2}$, sendo posteriormente transformadas para $\mathrm{kg} \mathrm{ha}^{-1}$. Os dados foram analisados pela estatística descritiva, a fim de verificar os parâmetros de tendência central e dispersão. A variabilidade espacial foi determinada pelo cálculo do semivariograma e construção de mapas de contorno por meio dos valores obtidos na interpolação por krigagem ordinária. Houve dependência espacial para os teores foliares de alguns nutrientes e para a produtividade de grãos de soja passível de ser mapeada em uma área com cerca de 2 ha, adubada de maneira homogênea. A dependência espacial não ocorreu de forma constante ao longo do tempo, o que deve ser considerado em estudos com cultivos sequenciais. A dependência espacial da produtividade de soja aumentou entre os anos estudados. Entre os nutrientes aplicados anualmente, via adubação, verificou-se a formação de um padrão de distribuição espacial, em 1986 e em 1988, especialmente para os teores de $P$.
\end{abstract}

Termos de indexação: diagnose foliar, geoestatística, sistema plantio direto.

\footnotetext{
(1) Trabalho apresentado no XXXII Congresso Brasileiro de Ciência do Solo, Fortaleza (CE), 2009. Recebido para publicação em novembro de 2009 e aprovado em agosto de 2010.

(2) Pesquisador Científico do Instituto Agronômico (IAC), Campinas, SP. Caixa Postal 28, CEP 13020-902 Campinas (SP). Emails: sidney@iac.sp.gov.br; mkchiba@iac.sp.gov.br; evmellis@iac.sp.gov.br; dechen@iac.sp.gov.br; icdmaria@iac.sp.gov.br

${ }^{(3)}$ Doutorando em Solos e Nutrição de Plantas, Escola Superior de Agricultura "Luiz de Queiroz" - ESALQ/USP. Caixa Postal 09, CEP 13418-900 Piracicaba (SP). E-mail: osvaldoguedes@yahoo.com.br
} 


\title{
SUMMARY: SPATIAL VARIABILITY OF LEAF NUTRIENT CONTENT AND SOYBEAN YIELD GROWN FOR TWO YEARS IN A RHODIC HAPLUDOX
}

\begin{abstract}
The chemical analysis of plant tissue is an efficient method to assess the nutritional status. This study aimed to characterize the spatial variability of plant nutrients and soybean yield in an experimental area (120 x $160 \mathrm{~m}$, totaling $1.92 \mathrm{ha}$ ) of a Rhodic Hapludox under no tillage for two years. Soybean leaf and grain yield were sampled at 63 points in a regular $20 \mathrm{~m}$ grid. Plant nutrient contents ( $N, P, K, C a, M g, C u, F e, M n$, and $\mathrm{Zn}$ ) were determined analyzing

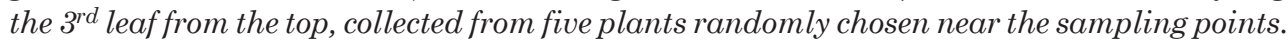
The crop yield was measured in $5 \mathrm{~m}^{2}$ subplots and expressed in $\mathrm{kg} \mathrm{ha}^{-1}$. Data were analyzed using descriptive statistics to assess the measures of central tendency and dispersion. Spatial variability was analyzed using semivariogram parameters and contour maps based on interpolation by ordinary kriging. Spatial dependence was observed for some foliar nutrient contents and crop productivity in a homogeneously fertilized area of about 2 ha. Spatial dependence was not constant over time, which should be taken into account in studies with sequential crops. The spatial dependence of soybean yield increased in the two years studied. Among the nutrients applied annually by fertilization, the formation of a spatial pattern was observed in 1986 and 1988, especially for $P$.
\end{abstract}

Index terms: foliar diagnosis, geostatistics, no tillage system.

\section{INTRODUÇÃO}

O manejo convencional da fertilidade do solo baseiase na utilização de teores médios de referência dos nutrientes para o cálculo da dose de fertilizante a ser aplicada em glebas selecionadas e separadas por serem as mais homogêneas entre si. Apesar dessa preocupação, é comum a ocorrência de valores extremos de alguns elementos químicos localizados espacialmente, sobretudo daqueles de menor mobilidade no solo (p.e., P), de modo que a utilização de valores médios pode resultar na aplicação de doses superestimadas em determinadas áreas e insuficientes em outras (Cavalcante et al., 2007; Souza et al., 2007). Essas variações nos teores de nutrientes no solo normalmente resultam em "manchas de fertilidade", que podem conduzir a um estado de nutrição diferenciado nas plantas, incrementando a variação na produção, tendo em vista a relação entre teor de nutrientes no tecido vegetal (p.e., nas folhas) e o crescimento e desenvolvimento da planta (Bernardi et al., 2002).

Apesar de a análise química do tecido vegetal fornecer um panorama da nutrição da planta num estádio avançado de desenvolvimento, essa é sem dúvida uma das melhores formas de se avaliar a disponibilidade dos nutrientes no solo, pois utiliza-se a planta como extrator de elementos químicos do solo. Para a cultura da soja, Malavolta (2006) estabeleceu faixas de suficiência para os nutrientes $\mathrm{N}\left(55-58 \mathrm{~g} \mathrm{~kg}^{-1}\right), \mathrm{P}\left(4-5 \mathrm{~g} \mathrm{~kg}^{-1}\right)$, $\mathrm{K}\left(22-25 \mathrm{~g} \mathrm{~kg}^{-1}\right), \mathrm{Ca}\left(9-10 \mathrm{~g} \mathrm{~kg}^{-1}\right), \mathrm{Mg}\left(3,5-4,0 \mathrm{~g} \mathrm{~kg}^{-1}\right)$, $\mathrm{S}\left(2,5-3,5 \mathrm{~g} \mathrm{~kg}^{-1}\right), \mathrm{B}\left(40-45 \mathrm{~g} \mathrm{~kg}^{-1}\right), \mathrm{Cu}\left(12-15 \mathrm{mg} \mathrm{kg}^{-1}\right), \mathrm{Fe}$ (125-150 mg kg-1), Mn (35-50 mg kg-1) e Zn (50$70 \mathrm{mg} \mathrm{kg}^{-1}$ ), com vistas a melhor entender ou interpretar os resultados da diagnose foliar.
Uma das opções de manejo utilizadas para minimizar os efeitos da variabilidade na produtividade das culturas é a agricultura de precisão, que representa um conjunto de técnicas e procedimentos utilizados para que os sistemas de produção agrícola sejam otimizados, tendo como objetivo principal o gerenciamento da variabilidade espacial (Molin, 2000). Para isso, na agricultura de precisão é importante a caracterização e a descrição da variabilidade espacial dos teores foliares de nutrientes e da produtividade das culturas, visando à correlação desses dados para auxiliar o manejo da adubação, sobretudo no que se refere à aplicação localizada e em taxas variáveis de fertilizantes.

$\mathrm{Na}$ caracterização dessa variabilidade, a geoestatística tem sido relatada como uma ferramenta eficiente, possibilitando a interpretação dos resultados com base na estrutura da variabilidade obtida nos semivariogramas (Vieira, 2000; Vieira et al., 2002; Carvalho et al., 2002). A análise geoestatística permite conhecer a variabilidade espacial dos teores foliares de nutrientes, e seu emprego fornece informações importantes quanto ao planejamento e manejo das áreas cultivadas (Souza et al., 1997; Bernardi et al., 2002; Resende et al., 2005). Apesar da importância da descrição espacial do conteúdo foliar de nutrientes como ferramenta para caracterizar a fertilidade do solo por meio de cálculos geoestatísticos, poucos estudos foram conduzidos nesse sentido, principalmente ao longo do tempo.

A hipótese de trabalho estudada é a de que, para uma mesma espécie vegetal, não há estrutura de dependência espacial dos teores de nutrientes, tendo em vista que estes foram aplicados homogeneamente em toda a área. O objetivo deste trabalho foi 
caracterizar a variabilidade espacial dos teores foliares de nutrientes e da produtividade da soja cultivada num Latossolo Vermelho sob sistema semeadura direta durante dois anos.

\section{MATERIAL E MÉTODOS}

O experimento foi realizado no Centro Experimental Central do Instituto Agronômico, em Campinas/SP, numa área com 1,92 ha (120 x 160 m), declividade média de $10 \%$ e altitude relativa de aproximadamente $630 \mathrm{~m}$ (Figura 1). As coordenadas geográficas da área são de $22^{\circ} 53^{\prime} \mathrm{S}$ e $47^{\circ} 04^{\prime} \mathrm{W}$, e o solo foi classificado como Latossolo Vermelho distroférrico A moderado textura argilosa, segundo o Sistema Brasileiro de Classificação de Solos (Embrapa, 2006). De acordo com a classificação climática internacional de Köppen, a região de Campinas apresenta transição entre os tipos climáticos Cwa e Cfa, característica de clima tropical de altitude. Os dados climáticos registrados durante a condução do experimento (Figura 2) foram obtidos no Centro de Ecofisiologia e Biofísica do IAC.

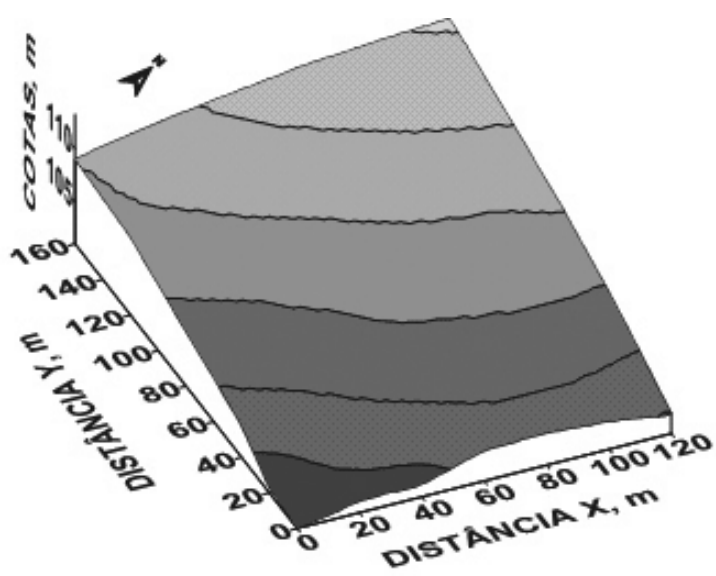

$\begin{array}{lllllll}101 & 103 & 105 & 107 & 109 & 111 & 113\end{array}$

Figura 1. Cotas topográficas da área experimental.

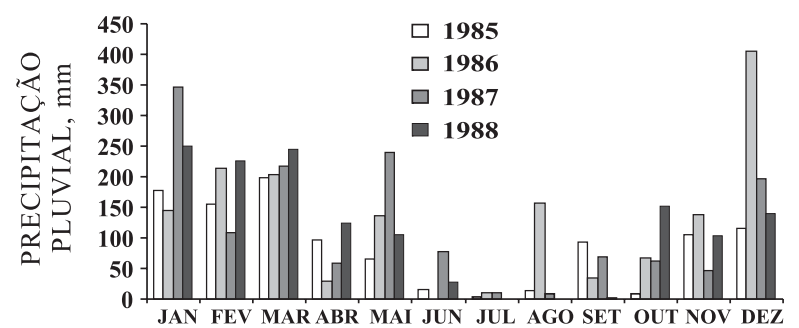

Figura 2. Dados pluviométricos da área experimental de 1985 a 1988. Centro Experimental Central do IAC - Fazenda Santa Elisa, Campinas/SP.
Segundo o histórico de uso da área estudada, o local esteve em pousio, sem qualquer cultivo, no período entre 1975 e 1985 . O sistema plantio direto (SPD) foi implantado na área em 1985 e, para isso, em março daquele ano a área foi limpa e semeada com crotalária (Crotalaria juncea), sem qualquer tipo de adubo, procurando homogeneizar as características químicas do solo. Em setembro de 1985 a crotalária foi cortada e incorporada ao solo, que, na sequência, foi subsolado, arado e gradeado. A correção da acidez foi realizada com a calagem, aplicando calcário dolomítico $(\mathrm{PRNT}=67 \%)$ em dose suficiente para elevar a saturação por bases para 60 \%. Em novembro de 1985 foi semeada a soja, utilizando, como adubação de plantio, $350 \mathrm{~kg} \mathrm{ha}^{-1}$ do formulado NPK 0-28-15. Desde então, o histórico de uso do solo incluiu a sucessão de culturas: soja (verão de 1985), centeio (inverno de 1986), milho (verão de 1986), aveia-preta (inverno de 1987) e soja (verão de 1987). Esta última foi semeada utilizando-se a mesma adubação de plantio descrita para a soja plantada em 1985.

Neste estudo estão sendo considerados os teores foliares e a produtividade de grãos no ano agrícola 1985-86 (doravante referido como soja-86) e no ano agrícola 1987-88 (doravante referido como soja-88).

A coleta de amostras foliares e a quantificação da produção da soja foram realizadas seguindo uma grade amostral distribuída em espaçamento regular de $20 \mathrm{~m}$, totalizando 63 pontos. A produção de grãos de soja foi quantificada em subparcelas de $5 \mathrm{~m}^{2}$, sendo posteriormente expressa em kg ha-1. Para quantificação dos teores foliares de nutrientes, foi coletada a terceira folha com pecíolo a partir do ápice de cinco plantas escolhidas ao acaso, em torno de cada um dos pontos de amostragem. As folhas foram lavadas sequencialmente: uma vez em solução diluída a $0,1 \% \mathrm{v} / \mathrm{v}$ de detergente neutro, duas vezes em água de torneira e uma vez em água destilada, secas em estufa de circulação forçada de ar por $72 \mathrm{~h}$, moídas e analisadas para o teor de macronutrientes $(\mathrm{N}, \mathrm{P}, \mathrm{K}$, $\mathrm{Ca}$ e $\mathrm{Mg}$ ) e de micronutrientes (Cu, Fe, Mn e Zn), segundo o método descrito por Bataglia et al. (1983).

Os dados foram analisados pela estatística descritiva, por meio dos seguintes parâmetros: média, variância, coeficiente de variação $(\mathrm{CV})$, assimetria e curtose, os quais possibilitaram verificar a existência de tendência central; o ajuste dos dados à distribuição do tipo normal foi avaliado pelo teste de KolmogorovSmirnov a $5 \%$. Para caracterizar a variabilidade espacial dos teores foliares de nutrientes e das produtividades de soja, os dados foram analisados, utilizando métodos geoestatísticos por meio do cálculo de semivariogramas, conforme instruções de Vieira (2000), partindo das pressuposições de existência de estacionaridade da hipótese intrínseca. A autocorrelação espacial entre locais vizinhos foi calculada por meio da semivariância $\gamma(\mathrm{h})$, conforme a equação 1: 


$$
\gamma^{*}(h)=\frac{1}{2 N(h)} \sum_{i=1}^{N(h)}\left[Z\left(x_{i}\right)-Z\left(x_{i}+h\right)\right]^{2}
$$

em que $N(h)$ é o número de pares de valores medidos $Z\left(x_{i}\right), Z\left(x_{i}+h\right)$, separados por um vetor $h$.

O cálculo da equação 1 gera valores de $\gamma(\mathrm{h})$ correspondentes a distâncias h e, segundo Vieira (2000), é esperado que medições realizadas em locais próximos sejam mais parecidas entre si do que aquelas separadas por grandes distâncias. Dessa forma, a $\gamma(\mathrm{h})$ aumenta com a distância até um valor máximo, a partir do qual se estabiliza em um patamar correspondente à distância-limite de dependência espacial, que é o alcance.

Os ajustes dos modelos experimentais ao semivariograma basearam-se no maior valor do coeficiente de determinação e no menor valor da raiz quadrada do erro médio, e a escolha do melhor ajuste foi feita utilizando a técnica de validação conhecida por jack-knifing, de acordo com Vieira et al. (2002). Além disso, observaram-se em cada modelo os menores valores da raiz quadrada do erro médio quadrático (RMSE) e o maior coeficiente de determinação $\left(\mathrm{R}^{2}\right)$.

Do ajuste de um modelo matemático aos dados, foram definidos os parâmetros do semivariograma: (a) efeito pepita $\left(\mathrm{C}_{0}\right)$, que é o valor de $\gamma$ quando $\mathrm{h}=0$; $(\mathrm{b})$ alcance da dependência espacial (a), que é a distância em que $\gamma(\mathrm{h})$ permanece aproximadamente constante, após aumentar com o aumento de h; e c) patamar $\left(\mathrm{C}_{0}+\mathrm{C} 1\right)$, que é o valor de $\gamma(\mathrm{h})$ a partir do alcance e que se aproxima da variância dos dados, se ela existe. Quando o semivariograma apresentou tendência, ou seja, não se estabilizou num patamar com a distância crescendo ininterruptamente, foi ajustada uma superfície polinomial, calculada conforme Davis (1973), e realizou-se novo ajuste com os resíduos obtidos pela diferença entre os dados originais e a superfície ajustada.

Para expressar a dependência espacial de uma variável, foi utilizado o grau de dependência espacial (GD), que mede a proporção da variância estruturada $\left(\mathrm{C}_{1}\right)$ em relação ao patamar $\left(\mathrm{C}_{0}+\mathrm{C}_{1}\right)$ e pode ser calculado pela equação 2 :

$$
G D=\left(\frac{C_{1}}{C_{0}+C_{1}}\right) \cdot 100
$$

De acordo com Zimback (2001), o GD pode ser usado para classificar a dependência espacial em fraca (GD $<25 \%)$, moderada $(25 \% \leq \mathrm{GD}<75 \%)$ e forte $(\mathrm{GD} \geq$ $75 \%$ ). Quando comprovada a autocorrelação espacial entre as amostras por meio da análise dos semivariogramas, foram elaborados mapas de contorno utilizando a krigagem ordinária como técnica de interpolação. A análise geoestatística foi realizada com o conjunto de softwares GEOSTAT (Vieira et al., 2002), e a construção dos mapas de variabilidade foi feita utilizando o software SURFER 7.0 (Golden
Software, 1999). Foram procuradas correlações significativas entre produtividade e teor foliar para cálculo de semivariogramas cruzados e posterior interpolação por cokrigagem, o que permitiria inferir a produção de grãos a partir do teor de nutrientes no tecido vegetal.

\section{RESULTADOS E DISCUSSÃO}

Conforme o critério de classificação do coeficiente de variação (CV) proposto por Warrick \& Nielsen (1980), para os dados de 1986, apenas o teor foliar de Mn e a produtividade da soja apresentaram CVs classificados como altos, em torno de $27 \%$ (Quadro 1). Para os dados de 1988, os valores de CV podem ser classificados como baixos a médios, seguindo o mesmo critério. Esses resultados são semelhantes aos obtidos por Bernardi et al. (2002), indicando assim que os teores foliares de nutrientes para uma mesma espécie vegetal ou cultivar tendem a se manter dentro de uma determinada faixa de variação.

Os dados foram submetidos ao teste de KolmogorovSmirnov a $5 \%$, para testar o ajuste dos dados à distribuição do tipo normal (Quadro 1). Todas as variáveis estudadas apresentaram ajuste do tipo normal, com valores da estatística D inferiores ao valor crítico do teste K-S e igual a 0,168. A análise geoestatística não exige que os dados apresentem distribuição de frequências do tipo normal, mas a identificação da ocorrência de distribuições muito assimétricas é interessante no sentido de que a krigagem ordinária pode ser considerada uma estimativa baseada em médias móveis ponderadas (Isaaks \& Srivastava, 1989), com pesos calculados a partir de semivariogramas.

Em 1986, os valores médios $(n=63)$ dos teores da maioria dos nutrientes encontravam-se abaixo dos valores de referência, tidos como adequados para o crescimento e desenvolvimento da soja segundo Malavolta (2006). Em 1988, apesar da reposição de nutrientes pela adubação, isso persistiu para o teor de $\mathrm{P}$ e Fe, ao passo que o Mn apresentou-se em teores médios acima do nível crítico considerado. Como a área estudada não vinha sendo utilizada com soja, o aumento nos teores foliares de $\mathrm{N}$ de 1986 para 1988 pode ser explicado pela adaptação da população microbiana, notadamente rizobactérias fixadoras de $\mathrm{N}_{2}$. Isso pode ser apoiado pelo fato de que houve correlação linear significativa e positiva ( $\rho=0,223$; $\mathrm{p}<0,05$ ) entre produção de grãos e $\mathrm{N}$ foliar apenas para os dados de 1986.

Concomitantemente, o aumento nos teores foliares de $\mathrm{Cu}$ e $\mathrm{Zn}$ com o tempo pode ser explicado pela gradual diminuição do pH (dados não mostrados), tendo em vista que a calagem foi efetuada na implantação do SPD em 1985, não sendo repetida desde então. Essa assertiva pode ser corroborada pela redução nos teores de $\mathrm{Ca}$ e $\mathrm{Mg}$, cuja única fonte foi a 
calagem (Quadro 1). Adicionalmente, como não foi realizada adubação com micronutrientes, esses elementos já estavam presentes no solo e a sua disponibilidade somente poderia ser alterada em função do efeito indireto da variação de outro atributo, como o pH. Isso também está de acordo com a existência de correlação positiva e significativa entre produção de grãos e P foliar ( $\rho=0,301 ; p<0,05)$ em 1988.

Para quase todos os elementos analisados verificouse uma estrutura de dependência espacial definida por semivariogramas ajustados aos modelos esférico e, ou, exponencial (Quadro 2). As variáveis P e Mn em 1986 apresentaram tendência, que foi retirada conforme procedimentos descritos por Davis (1973), e o semivariograma experimental foi ajustado aos resíduos.

Bernardi et al. (2002) também encontraram ajustes de semivariogramas a esses dois modelos quando estudaram os teores foliares de nutrientes em soja, o que indica que os modelos esférico e exponencial podem ser utilizados para explicar o comportamento espacial dessas variáveis.

Apenas um elemento $(\mathrm{N})$ não apresentou estrutura de dependência espacial em 1986. Isso também foi verificado para o Ca e para o $\mathrm{Mn}$ em 1988, caracterizando o que se denomina de "efeito pepita puro". Esses resultados diferem dos apresentados por Bernardi et al. (2002), que relataram ajustes para todos os nutrientes estudados em soja cultivada sob SPD em um Latossolo Vermelho distroférrico.
É conveniente destacar que os resultados obtidos neste trabalho indicam existir, para alguns nutrientes, uma estrutura de variabilidade dependente da localização espacial mesmo para uma área adubada com um mesmo formulado NPK. É um indicativo de que outros fatores estão interagindo, condicionando absorção de nutrientes de maneira diferenciada dentro da área experimental, e de que a utilização da média aritmética não representaria adequadamente o estado nutricional da soja.

Deve-se salientar também que os valores da dependência espacial medidos pelo grau de dependência (GD), para a produtividade de grãos, aumentaram de 1986 para 1988 (Quadro 2). Isso implica redução do componente relacionado com a variação aleatória $\left(\mathrm{C}_{0}\right)$ e o incremento do componente associado com a variação estruturada $\left(\mathrm{C}_{1}\right)$. Assim, nesse caso, é esperado que o fenômeno descrito pelos semivariogramas ajustados possa ser adequadamente espacializado por interpolação, identificando zonas de manejo com produção e teores foliares diferenciados. A análise do grau de dependência espacial permitiu classificar os teores foliares da maioria dos nutrientes e da produtividade da soja, nos dois anos estudados, como apresentando GD forte ou moderado (Quadro 2).

O alcance da dependência espacial é um parâmetro importante para a interpretação dos semivariogramas porque indica a distância máxima até onde os pontos amostrais estão correlacionados entre si, ou seja, quanto maior o alcance, maior a homogeneidade entre

Quadro 1. Parâmetros da estatística descritiva do teor foliar de nutrientes e da produtividade da soja, sob plantio direto

\begin{tabular}{|c|c|c|c|c|c|c|c|}
\hline Atributo & Média & Variância & DP & CV & $\mathbf{C}_{\text {sk }}$ & $\mathbf{C}_{\mathbf{k}}$ & Valor D \\
\hline & & & 1986 & & & & \\
\hline $\mathrm{N}\left(\mathrm{g} \mathrm{kg}^{-1}\right)$ & 44,7 & 20,9 & 4,6 & 10,2 & $-1,10$ & 2,54 & 0,109 \\
\hline $\mathrm{P}\left(\mathrm{g} \mathrm{kg}^{-1}\right)$ & 2,8 & 0,2 & 0,4 & 14,7 & 0,50 & 0,36 & 0,099 \\
\hline $\mathrm{K}\left(\mathrm{g} \mathrm{kg}^{-1}\right)$ & 24,3 & 2,5 & 1,6 & 6,6 & $-0,78$ & 1,55 & 0,119 \\
\hline $\mathrm{Ca}\left(\mathrm{g} \mathrm{kg}^{-1}\right)$ & 11,1 & 1,4 & 1,2 & 10,5 & 0,44 & 1,36 & 0,073 \\
\hline $\mathrm{Mg}\left(\mathrm{g} \mathrm{kg}^{-1}\right)$ & 3,8 & 0,1 & 0,3 & 9,2 & $-0,36$ & 0,09 & 0,113 \\
\hline $\mathrm{Fe}\left(\mathrm{mg} \mathrm{kg}^{-1}\right)$ & 116,9 & 337,0 & 18,4 & 15,7 & 0,78 & 4,18 & 0,095 \\
\hline $\operatorname{Mn}\left(\mathrm{mg} \mathrm{kg}^{-1}\right)$ & 112,3 & 916,1 & 30,3 & 26,9 & 0,55 & $-0,45$ & 0,138 \\
\hline $\mathrm{Cu}\left(\mathrm{mg} \mathrm{kg}^{-1}\right)$ & 10,5 & 0,7 & 0,8 & 8,0 & 0,67 & 1,99 & 0,097 \\
\hline $\mathrm{Zn}\left(\mathrm{mg} \mathrm{kg}^{-1}\right)$ & 43,5 & 14,5 & 3,8 & 8,8 & 0,84 & 1,53 & 0,127 \\
\hline \multirow[t]{2}{*}{ Prod. (kg ha-1) } & 1149 & 95150 & 308,5 & 26,8 & 0,12 & 0,46 & 0,095 \\
\hline & & & 1988 & & & & \\
\hline $\mathrm{N}\left(\mathrm{g} \mathrm{kg}^{-1}\right)$ & 57,6 & 7,7 & 2,8 & 4,8 & $-0,59$ & 0,44 & 0,105 \\
\hline $\mathrm{P}\left(\mathrm{g} \mathrm{kg}^{-1}\right)$ & 3,2 & 0,2 & 0,5 & 14,7 & $-1,07$ & 3,13 & 0,121 \\
\hline $\mathrm{K}\left(\mathrm{g} \mathrm{kg}^{-1}\right)$ & 22,3 & 4,3 & 2,1 & 9,2 & $-1,01$ & 1,98 & 0,166 \\
\hline $\mathrm{Ca}\left(\mathrm{g} \mathrm{kg}^{-1}\right)$ & 9,7 & 1,0 & 1,0 & 10,3 & $-0,37$ & 1,38 & 0,117 \\
\hline $\operatorname{Mg}\left(\mathrm{g} \mathrm{kg}^{-1}\right)$ & 3,4 & 0,1 & 0,4 & 11,4 & $-0,83$ & 0,99 & 0,133 \\
\hline $\mathrm{Fe}\left(\mathrm{mg} \mathrm{kg}^{-1}\right)$ & 116,8 & 112,7 & 10,6 & 9,1 & $-0,36$ & $-0,31$ & 0,102 \\
\hline $\operatorname{Mn}\left(\mathrm{mg} \mathrm{kg}^{-1}\right)$ & 96,6 & 292,8 & 17,1 & 17,7 & 2,77 & 13,41 & 0,147 \\
\hline $\mathrm{Cu}\left(\mathrm{mg} \mathrm{kg}^{-1}\right)$ & 11,9 & 1,3 & 1,2 & 9,8 & $-0,66$ & 0,48 & 0,149 \\
\hline $\mathrm{Zn}\left(\mathrm{mg} \mathrm{kg} \mathrm{kg}^{-1}\right)$ & 50,8 & 45,0 & 6,7 & 13,2 & 2,01 & 7,50 & 0,114 \\
\hline Prod. $\left(\mathrm{kg} \mathrm{ha}^{-1}\right)$ & 3135 & 367200 & 605,9 & 19,3 & 0,22 & $-0,48$ & 0,071 \\
\hline
\end{tabular}

DP: desvio-padrão; CV: coeficiente de variação (\%). Valor D: estatística do teste de Kolmogorv-Smirnov a 5 \%, para ajuste à distribuição normal; valor crítico de K-S $(\mathrm{p}<0,05=0,168) . \mathrm{C}_{\mathrm{sk}}$ : coeficiente de skwress; $\mathrm{C}_{\mathrm{k}}$ : coeficiente de curtose. 
Quadro 2. Parâmetros da análise semivariográfica do teor foliar de nutrientes e da produtividade da soja, sob plantio direto

\begin{tabular}{|c|c|c|c|c|c|c|c|}
\hline Atributo & Modelo & $\mathrm{C}_{0}$ & $\mathbf{C}_{1}$ & $\mathbf{A}$ & $\mathbf{R}^{2}$ & RMSE & GD \\
\hline & & & & $\mathrm{m}$ & & & $\%$ \\
\hline $\mathrm{N}\left(\mathrm{g} \mathrm{kg}^{-1}\right)^{2}$ & \multicolumn{7}{|c|}{$\begin{array}{l}1986 \\
\text { Efeito pepita puro }\end{array}$} \\
\hline $\mathrm{P}\left(\mathrm{g} \mathrm{kg}^{-1}\right)^{2}$ & $\operatorname{Exp}$ & 0,00 & 0,11 & 65,27 & 0,6355 & 0,0008 & 100,00 \\
\hline $\mathrm{K}\left(\mathrm{g} \mathrm{kg}^{-1}\right)^{2}$ & Exp & 1,00 & 1,58 & 36,03 & 0,0559 & 0,0351 & 61,23 \\
\hline $\mathrm{Ca}\left(\mathrm{g} \mathrm{kg}^{-1}\right)^{2}$ & Exp & 0,37 & 0,99 & 60,00 & 0,3841 & 0,0092 & 72,80 \\
\hline $\mathrm{Mg}\left(\mathrm{g} \mathrm{kg}^{-1}\right)^{2}$ & Esf & 0,0044 & 0,10 & 60,00 & 0,6168 & 0,0010 & 99,60 \\
\hline $\mathrm{Fe}\left(\mathrm{mg} \mathrm{kg}^{-1}\right)^{2}$ & Esf & 130,94 & 267,10 & 60,00 & 0,4628 & 3,1091 & 67,10 \\
\hline $\operatorname{Mn}\left(\mathrm{mg} \mathrm{kg}^{-1}\right)^{2}$ & Esf & 106,46 & 357,23 & 50,64 & 0,7507 & 1,7801 & 77,04 \\
\hline $\mathrm{Cu}\left(\mathrm{mg} \mathrm{kg}^{-1}\right)^{2}$ & Esf & 0,36 & 0,37 & 60,00 & 0,4446 & 0,0045 & 50,44 \\
\hline $\mathrm{Zn}\left(\mathrm{mg} \mathrm{kg}^{-1}\right)^{2}$ & Exp & 8,42 & 6,19 & 60,00 & 0,1248 & 0,1149 & 42,39 \\
\hline \multirow[t]{2}{*}{ Prod. $\left(\mathrm{kg} \mathrm{ha}^{-1}\right)^{2}$} & Exp & 38663,47 & 48655,87 & 38,94 & 0,0987 & 702,95 & 55,72 \\
\hline & \multicolumn{7}{|c|}{1988} \\
\hline $\mathrm{N}\left(\mathrm{g} \mathrm{kg}^{-1}\right)^{2}$ & Exp & 6,04 & 2,02 & 80,00 & 0,2558 & 0,0323 & 25,09 \\
\hline $\mathrm{P}\left(\mathrm{g} \mathrm{kg}^{-1}\right)^{2}$ & Esf & 0,08 & 0,16 & 80,00 & 0,6636 & 0,0016 & 67,06 \\
\hline $\mathrm{K}\left(\mathrm{g} \mathrm{kg}^{-1}\right)^{2}$ & $\operatorname{Exp}$ & 2,67 & 1,36 & 80,00 & 0,1587 & 0,0277 & 33,80 \\
\hline $\mathrm{Ca}\left(\mathrm{g} \mathrm{kg}^{-1}\right)^{2}$ & \multicolumn{7}{|c|}{ Efeito pepita puro } \\
\hline $\mathrm{Mg}\left(\mathrm{g} \mathrm{kg}^{-1}\right)^{2}$ & Esf & 0,009 & 0,138 & 60,00 & 0,6934 & 0,0011 & 94,12 \\
\hline $\mathrm{Fe}\left(\mathrm{mg} \mathrm{kg}^{-1}\right)^{2}$ & Esf & 35,15 & 88,70 & 60,00 & 0,6526 & 0,8243 & 71,62 \\
\hline $\operatorname{Mn}\left(\mathrm{mg} \mathrm{kg}^{-1}\right)^{2}$ & \multicolumn{7}{|c|}{ Efeito pepita puro } \\
\hline $\mathrm{Cu}\left(\mathrm{mg} \mathrm{kg}^{-1}\right)^{2}$ & Esf & 0,37 & 0,89 & 90,00 & 0,7734 & 0,0075 & 70,83 \\
\hline $\mathrm{Zn}\left(\mathrm{mg} \mathrm{kg}^{-1}\right)^{2}$ & Esf & 8,27 & 33,32 & 80,00 & 0,5739 & 0,4400 & 80,12 \\
\hline Prod. $\left(\mathrm{kg} \mathrm{ha}^{-1}\right)^{2}$ & Esf & 117999,26 & 287832,38 & 60,00 & 0,8070 & 1775,18 & 70,92 \\
\hline
\end{tabular}

$\mathrm{C}_{0}$ : efeito pepita; $\mathrm{C}_{1}$ : variância estruturada; A: alcance; GD: grau de dependência espacial; Exp.: modelo exponencial; Esf.: modelo esférico; EEP: efeito pepita puro; _res: utilização dos resíduos após correção de tendência por ajuste polinomial. A: alcance; RMSE: root mean squared error.

as amostras. Foram observados valores de alcance maiores que $36 \mathrm{~m}$ para os dados coletados em $1986 \mathrm{e}$ maiores que $60 \mathrm{~m}$ para os dados de 1988 (Quadro 2), mostrando que a distância de $20 \mathrm{~m}$, utilizada na amostragem, foi suficiente para expressar a variabilidade espacial tanto dos teores foliares de nutrientes quanto da produtividade de soja. Segundo Mulla \& McBratney (2000), unidades de amostragem podem ser definidas com extensões variando de 0,25 a 0,50 do valor do alcance, o que nesse caso representaria dimensões de $19,5 \mathrm{~m}$ para o alcance da produtividade da soja em $1986(38,94 \mathrm{~m})$ a $30 \mathrm{~m}$ para o alcance da produtividade em 1988 (60,0 m).

Nas figuras 3, 4, 5, 6 e 7 são apresentados os mapas interpolados por krigagem ordinária referentes ao teor de nutrientes e produtividade, respectivamente em 1986 e em 1988. Para o ano de 1986 não é apresentado o mapa referente ao teor de $\mathrm{N}$ foliar, uma vez que não foi possível ajustar um semivariograma, caracterizando a ocorrência de efeito pepita puro. Provavelmente isso está ligado ao fato de que na época não foi realizada a inoculação das sementes de soja com rizobactérias antes da semeadura. Borket et al. (1994) afirmaram que o elemento mais requerido pela soja é o $\mathrm{N}$, sendo necessários cerca de $264 \mathrm{~kg}$ de $\mathrm{N}$ para produzir $3.000 \mathrm{~kg}$ de grãos. Desse total, cerca de $30 \%$ seria proveniente do solo, e o restante, pela fixação simbiótica, demonstrando a importância da adequada inoculação das sementes de soja com rizhobium. Já em 1988 foi possível mapear os teores de $\mathrm{N}$ foliar, e os maiores valores, cerca de $60 \mathrm{~g} \mathrm{~kg}^{-1}$, ocorreram na parte leste (Figura 5a). Esses valores são pouco acima do considerado adequado por Malavolta (2006) e acima do valor médio verificado no ano de 1986 (Quadro 1). Como já citado, o aumento na disponibilidade de $\mathrm{N}$ com o tempo pode estar associado com a adaptação da população de rizobactérias fixadoras de $\mathrm{N}_{2}$.

O mapa de $\mathrm{P}$ foliar para os dados de 1986 permitiu identificar duas manchas distintas: uma na parte norte, com valores próximos a $4,0 \mathrm{~g} \mathrm{~kg}^{-1}$, e outra na parte sul, com valores menores e entre 2,0 e 2,5 g kg-1 (Figura 3a). Pode-se verificar claramente a formação de duas zonas com valores distintos de $\mathrm{P}$, e apenas na parte norte esses valores podem ser considerados adequados para a cultura (Malavolta, 2006). Esse fato foi verificado novamente na amostragem de 1988 (Figura 5b) e, dessa forma, é um indicativo de que a disponibilidade diferencial de $\mathrm{P}$ no solo esteja se refletindo nos teores foliares. Como a adubação é feita homogeneamente na semeadura, não haveria motivo para isso, e esse fato precisa ser mais bem investigado. Uma das hipóteses para explicar essa heterogeneidade está ligada ao histórico da área e relaciona-se com o fato de ter havido cultivo de videira até 1975, cujos limites são coincidentes com a zona de maior disponibilidade de P. De qualquer forma, verifica-se nítida diferenciação na localização da disponibilidade de P no solo, que por sua vez pode ser mapeada adotando-se procedimentos geoestatísticos, reforçando 


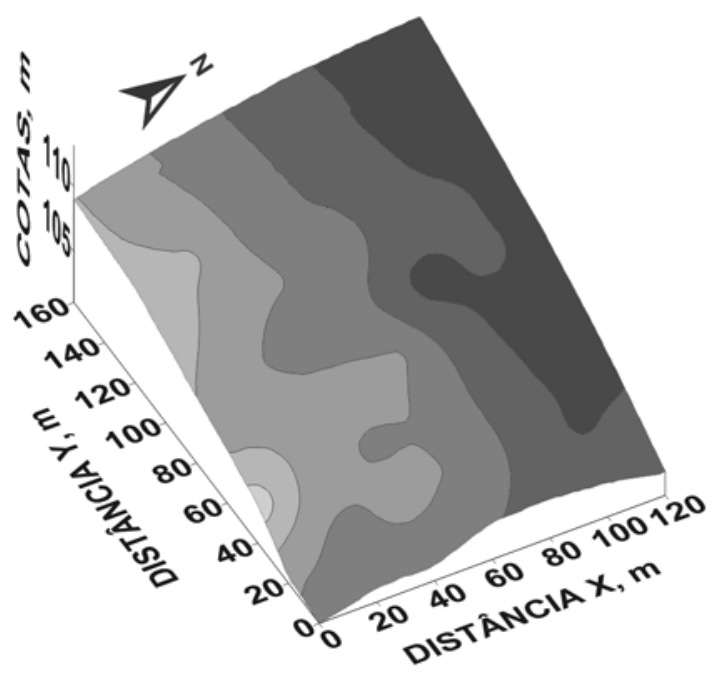

\section{Fósforo 86}

4.55 .05 .56 .06 .57 .07 .5

(a)
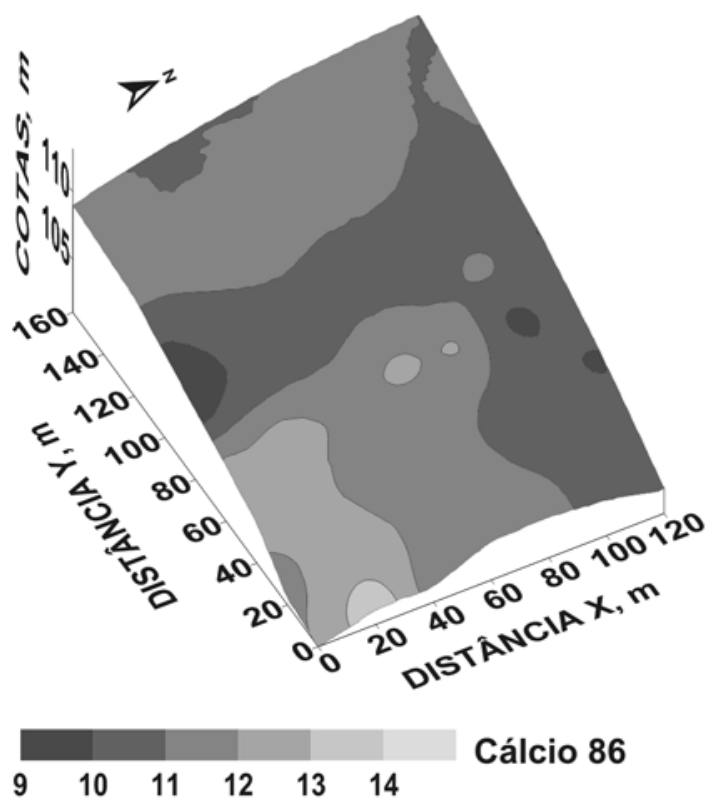

(c)

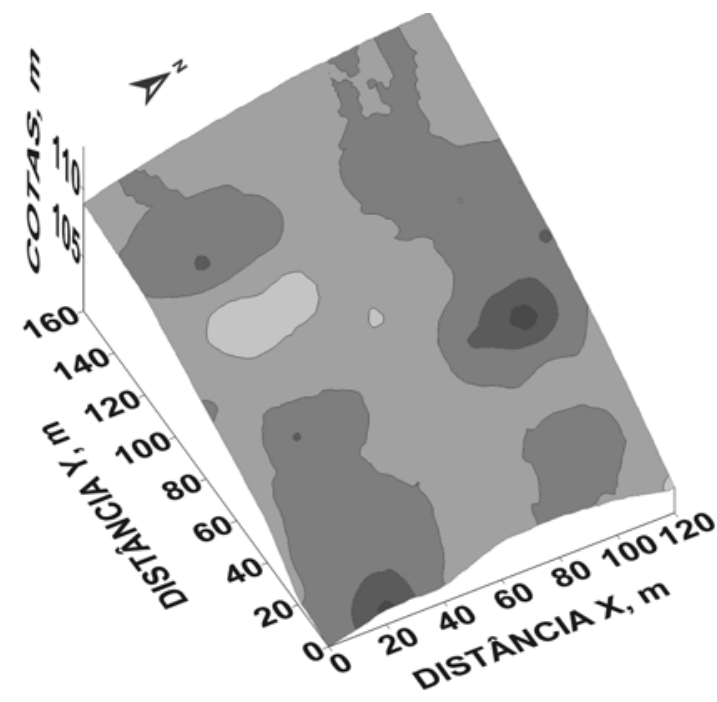

Potássio 86

(b)

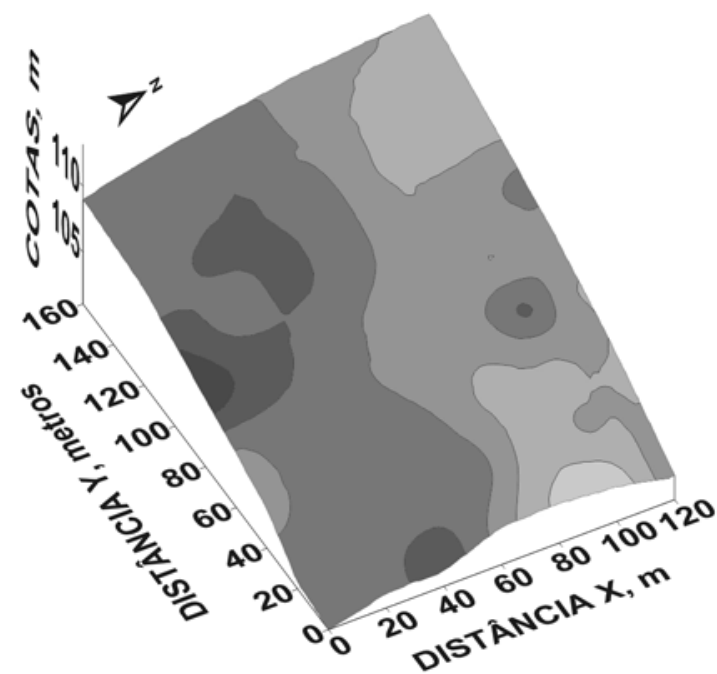

$\begin{array}{lllllll}2.8 & 3.1 & 3.4 & 3.7 & 4.0 & 4.3 & 4.6\end{array}$

Magnésio 86

(d)

Figura 3. Mapas de variabilidade espacial dos teores foliares de macronutrientes em 1986 (a: fósforo; b: potássio; c: cálcio; d: magnésio).

a tese de que a utilização do valor médio não fornece uma visão exata da população a partir da qual se pretende fazer inferências. Nesse caso, usando esse critério, os teores médios de $\mathrm{P}$ para toda a parcela experimental seriam de 2,8 e $3,2 \mathrm{mg} \mathrm{kg}^{-1}$, respectivamente em 1986 e 1988.

Os teores foliares de K em 1986 (Figura 3b) apresentaram distribuição espacial irregular, porém com predomínio de valores próximos a $25 \mathrm{~g} \mathrm{~kg}^{-1}$, ou seja, dentro da faixa de suficiência para os teores desse nutriente. Deve-se destacar que, ao menos visualmen- te, na comparação dos mapas de 1986 e 1988 houve inversão na distribuição de $\mathrm{K}$ foliar nas duas épocas estudadas. Como não há elementos que justifiquem essa diferença em termos de fenômenos associados com a disponibilidade do nutriente, é razoável supor que pequenas diferenças no ajuste das adubadoras estejam imprimindo essas variações na área experimental.

Os maiores teores de Ca ocorreram nos locais de menor cota topográfica em 1986, e praticamente toda a área experimental apresentou teores superiores ao 

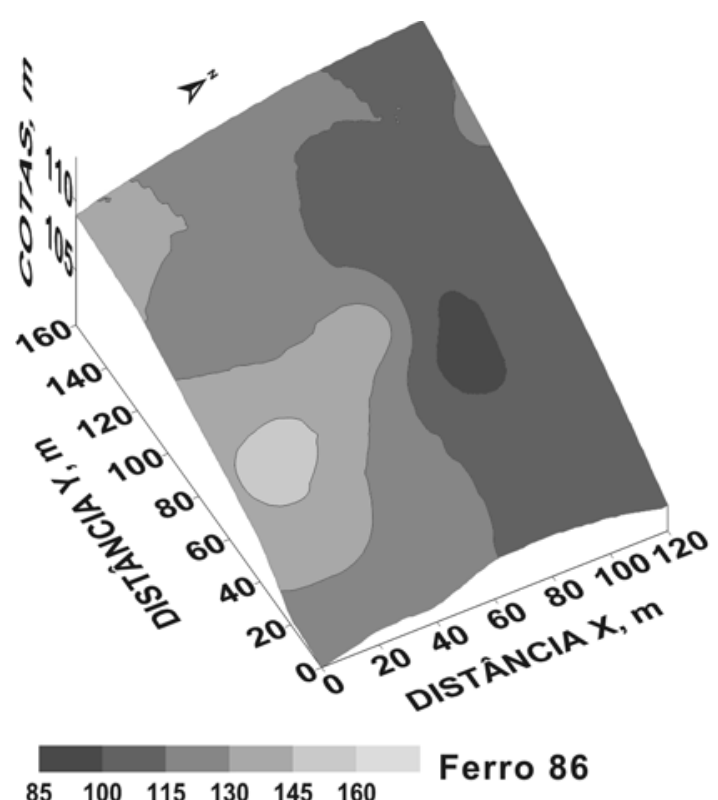

(a)

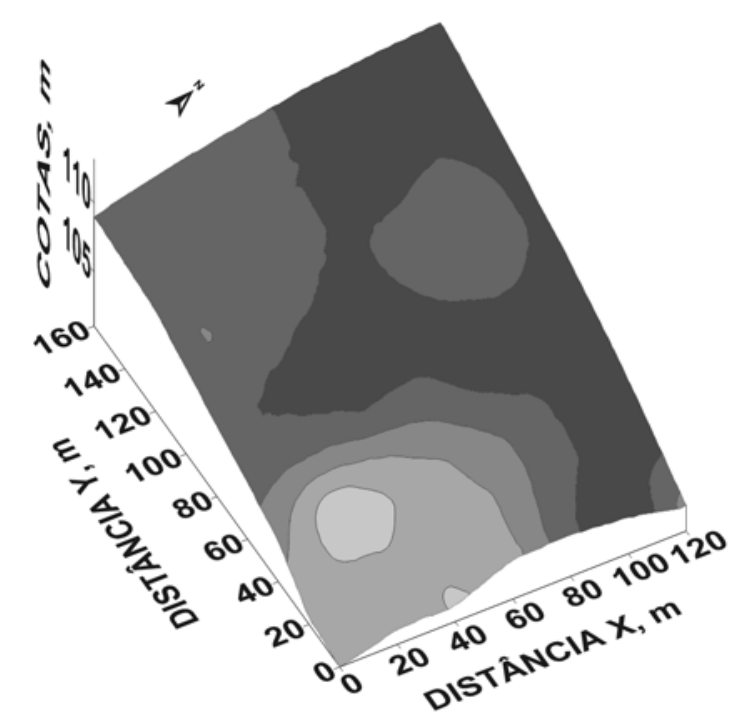

Cobre 86

(c)

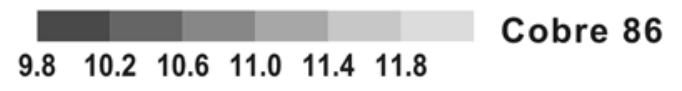

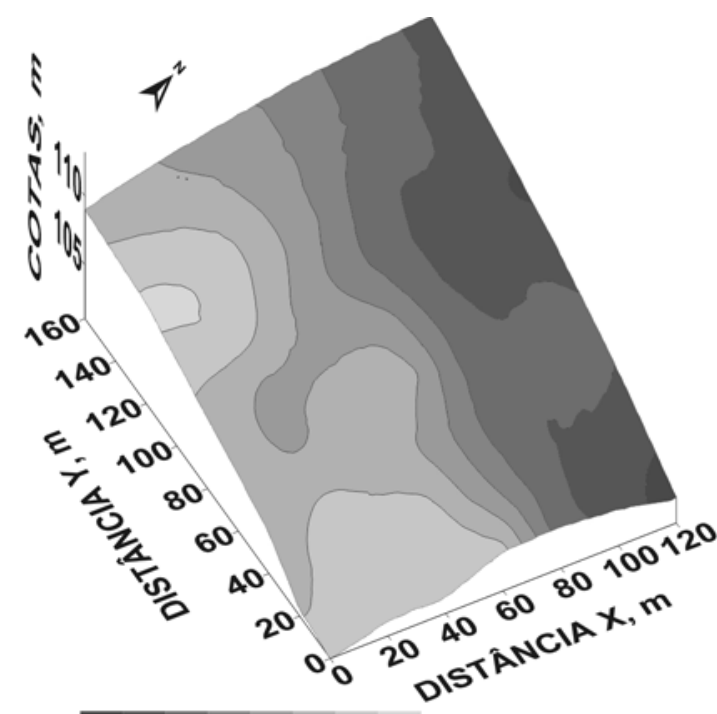

160180200220240260280300

Manganês 86

(b)

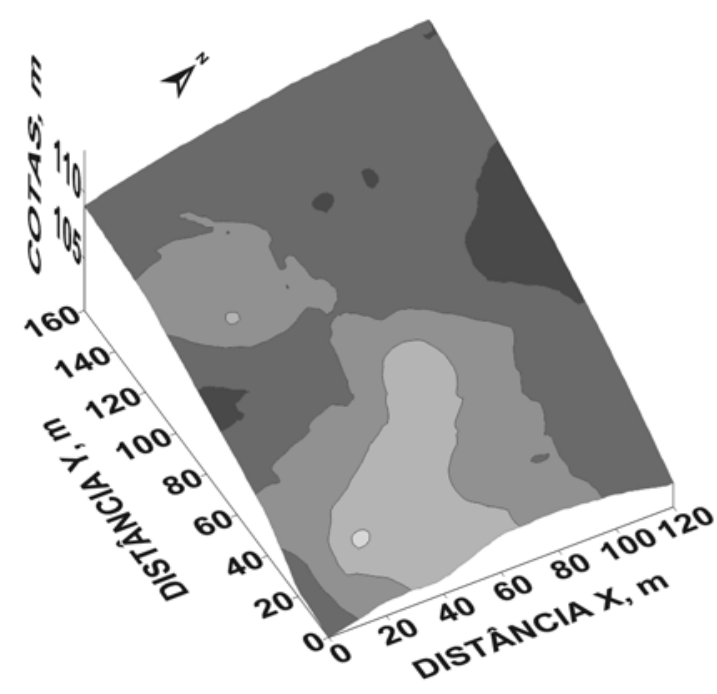

Zinco 86

Figura 4. Mapas de variabilidade espacial dos teores foliares de micronutrientes em 1986 (a: ferro; b: manganês; c: cobre; d: zinco).

considerado adequado (Figura 3c). O efeito da posição em relação à cota topográfica e ao teor de nutrientes nas folhas para o $\mathrm{Mg}$ mostrou que, nos dois anos estudados, os maiores teores foram obtidos nos pontos mais altos do terreno (Figuras 3d e 5d). Essa diferenciação nos teores foliares desses nutrientes não era esperada, porque a única fonte desses elementos foi o calcário, aplicado em área total e incorporado quando do início de adoção do SPD como sistema de manejo cultural.
Como a área experimental não recebeu fertilizantes com micronutrientes nos dois anos avaliados e havia sido cultivada por muito tempo com videira, cultura na qual a adubação é feita na linha de cultivo, era esperado que os teores foliares acompanhassem a disponibilidade desses elementos no solo e apresentassem elevada variabilidade espacial, fato esse confirmado conforme a figura 4a,b,c,d, respectivamente para $\mathrm{Fe}, \mathrm{Cu}, \mathrm{Mn}$ e $\mathrm{Zn}$ em 1986, e na figura 6a,b,c, respectivamente para Fe, Cu e Zn em 1988. 
Os teores foliares de Fe (Figuras 4a e 6a) e Mn (Figura 4b) apresentam semelhança na distribuição espacial, e em ambos os mapas a parte norte apresentou os maiores teores em comparação com a parte sul. Foram verificados teores de Mn foliar superiores ao adequado para toda a área estudada (Figura 4b), diferentemente do que foi observado para o $\mathrm{Fe}$, em que apenas a parte norte apresentou teores considerados adequados (Figura 4a; 6a). Dentro da área experimental foram verificadas variações de cerca
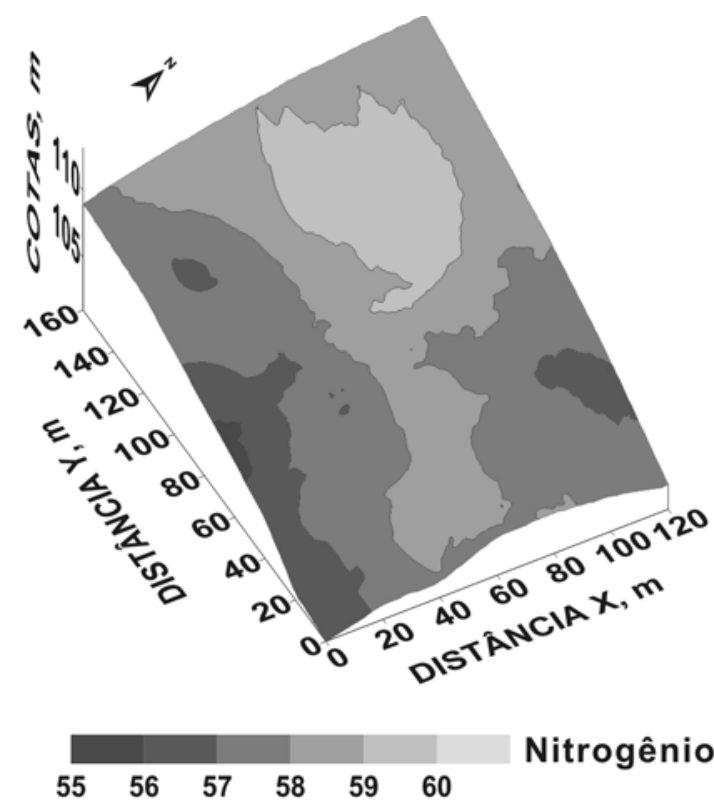

Nitrogênio 88

(a)

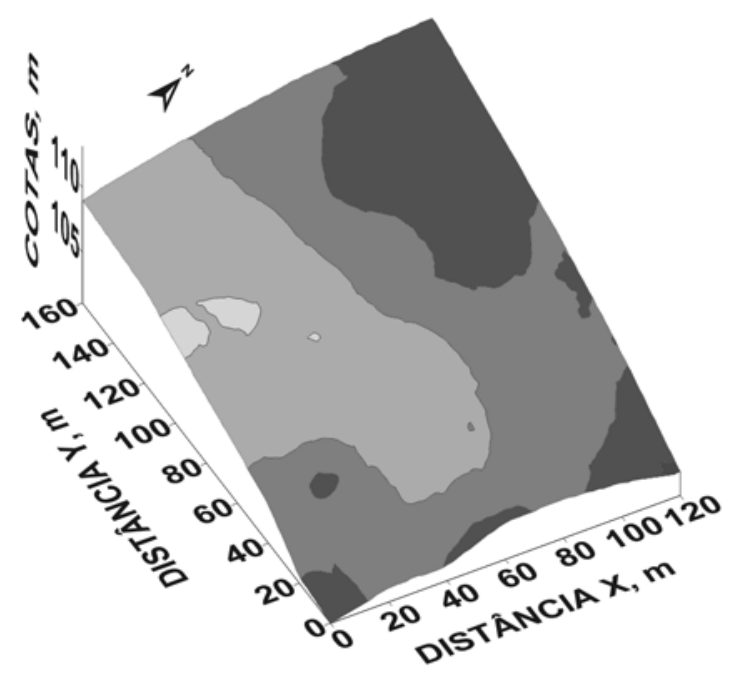

Potássio 88

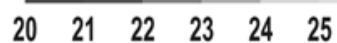

(c) de $82 \%$ nos teores de Fe ( 85 a $155 \mathrm{mg} \mathrm{kg}^{-1}$ ) em 1986 e de $33 \%$ (96 a $128 \mathrm{mg} \mathrm{kg}^{-1}$ ) em 1988. Para os teores de $\mathrm{Cu}$ (Figura 4c) e Zn (Figura 4d) em 1986, os maiores valores foram determinados nas posições com cotas topográficas mais baixas, enquanto em 1988 ocorreu o inverso (Figura 6b,c). Apesar das variações, todos os nutrientes estudados apresentaram-se dentro da faixa considerada adequada para a soja por Sfredo et al. (1986), que é de $40-55 \mathrm{~g} \mathrm{~kg}^{-1}$ de N; $2,6-5 \mathrm{~g} \mathrm{~kg}^{-1}$ de P; 17-25 g kg-1 de K; 3,6-20 $\mathrm{g} \mathrm{kg}^{-1}$ de Ca; 2,6-10 $\mathrm{g} \mathrm{kg}^{-1}$

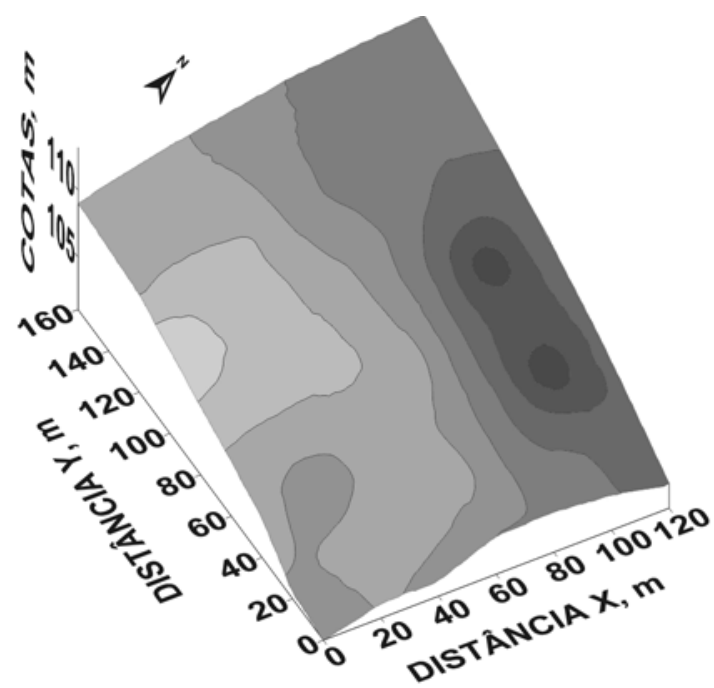

Fósforo 88

\subsection{2 .62 .83 .03 .23 .43 .63 .84 .0}

(b)

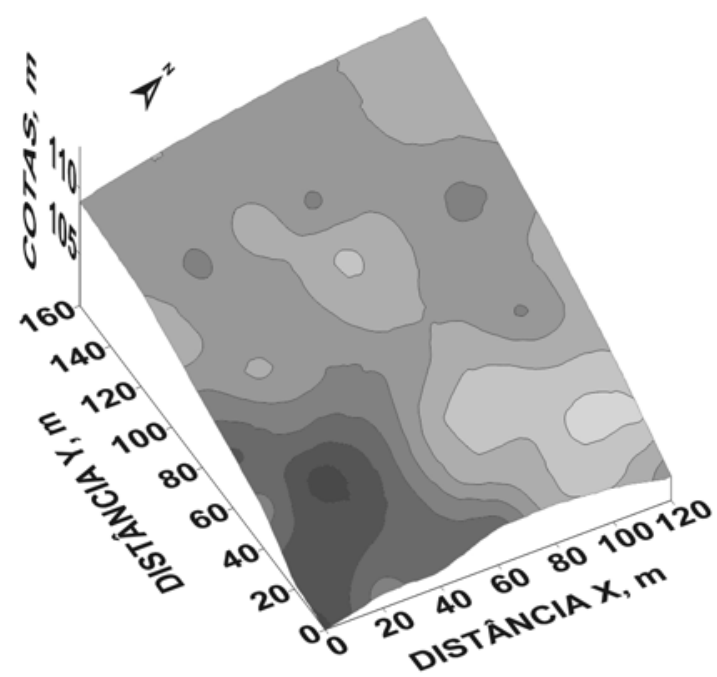

Magnésio 88

2.52 .72 .93 .13 .33 .53 .73 .9

(d)

Figura 5. Mapas de variabilidade espacial dos teores foliares de macronutrientes em 1988 (a: nitrogênio; b: fósforo; c: potássio; d: magnésio). 

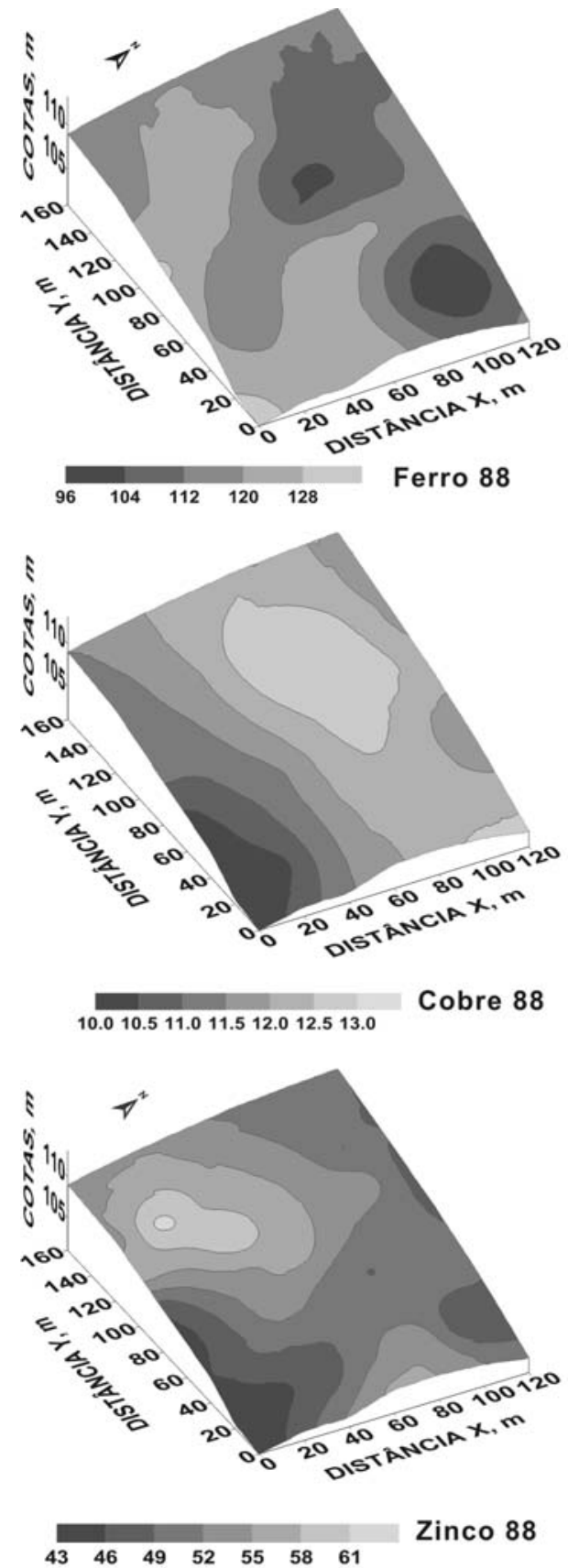

Figura 6. Mapas de variabilidade espacial dos teores foliares de micronutrientes em 1988 (a: ferro; b: cobre; c: zinco).

de $\mathrm{Mg} ; 10-30 \mathrm{mg} \mathrm{kg}^{-1} \mathrm{de} \mathrm{Cu}$; $51-350 \mathrm{mg} \mathrm{kg}^{-1}$ de Fe; 21-100 mg kg-1 de Mn; e 21-50 mg kg-1 de Zn.

Um dos fatores que podem ter contribuído para a obtenção de maiores teores foliares de $\mathrm{Ca}, \mathrm{Fe}, \mathrm{Mn}, \mathrm{Cu}$ e $\mathrm{Zn}$ nas cotas mais baixas no primeiro ano é o carreamento físico de partículas de calcário e material orgânico por escorrimento superficial, pois no primeiro ano de estabelecimento do experimento o preparo do solo foi realizado com aração e gradagem. Pode ser verificado que em setembro de 1985, antes da se-

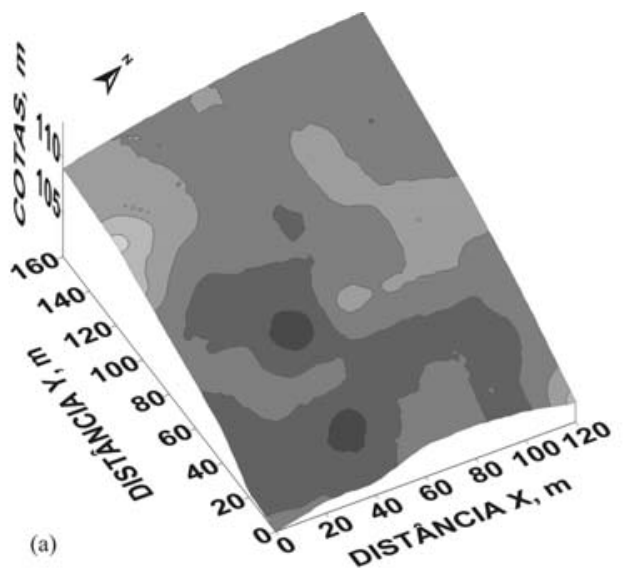

Soja 86

\section{0}

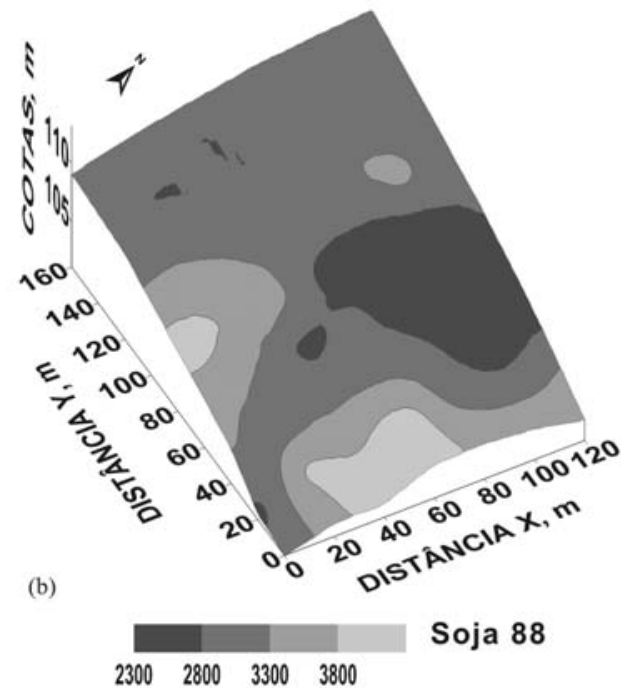

Figura 7. Mapas de variabilidade espacial da produtividade da soja em 1986 (a) e em 1988 (b).

meadura da soja naquele ano, houve precipitação pluvial anormal. Em 1987, as chuvas também iniciaram-se em setembro, mas não apresentaram a mesma variação acentuada nos meses seguintes (Figura 2).

A produtividade da soja apresentou maior variação no primeiro ano (Quadro 1 e Figura 7a,b) em comparação com a obtida em 1988, apesar de este período ter apresentado produção de grãos três vezes maior.

As áreas com as maiores produtividades em 1986 (p.e., sudeste e sudoeste) foram também as com os maiores teores foliares de K, mostrando que, quanto maior a disponibilidade desses nutrientes, maior a produtividade da cultura. Todavia, como não houve correlação linear significativa $(p>0,05)$ entre a produção de grãos de soja e os teores foliares de $\mathrm{K} \mathrm{em}$ 1986, essa relação espacial entre as variáveis não foi considerada. O mapa da produtividade da soja em 1988 mostrou similaridade do padrão espacial com os 
mapas de $\mathrm{P}$ e $\mathrm{K}$; em todos esses mapas a região norte apresentou os maiores teores foliares desses nutrientes, coincidindo com as maiores produtividades. Nesse caso, além da similaridade visual na distribuição espacial para o $\mathrm{P}$ e produção de grãos, houve correlação linear positiva e significativa $(r=0,301 ; p<0,05)$.

O uso do teor de $\mathrm{P}$ como variável auxiliar na estimativa da produção de grãos foi avaliado pelo semivariograma cruzado (Figura 8a) e, posteriormente, pela cokrigagem (Figura 8b). Apesar de o teor foliar de $\mathrm{N}$ também ter apresentado correlação significativa, tendo em vista a complexa dinâmica do nutriente na cultura da soja, optou-se por estudar neste caso o uso do $\mathrm{P}$ foliar como covariável. O semivariograma cruzado foi ajustado a um modelo esférico com os seguintes parâmetros de ajuste: $\mathrm{C}_{0}=0,10 ; \mathrm{C}_{1}=115,80$; $\mathrm{a}=91,20 \mathrm{~m} ; \mathrm{R}^{2}=0,844 ; \mathrm{e} \mathrm{GD}=99,91 \%$. Dada $\mathrm{a}$ importância do $\mathrm{P}$ na nutrição vegetal, o fato de se estimar a produção de grãos com base no seu teor foliar não surpreende tanto quanto a possibilidade de realizar essa inferência em uma área relativamente pequena: 1,92 ha.

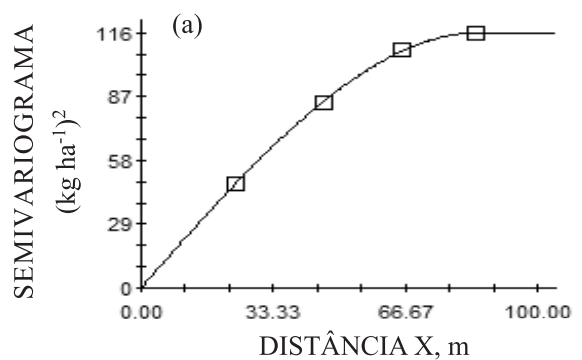

(b)
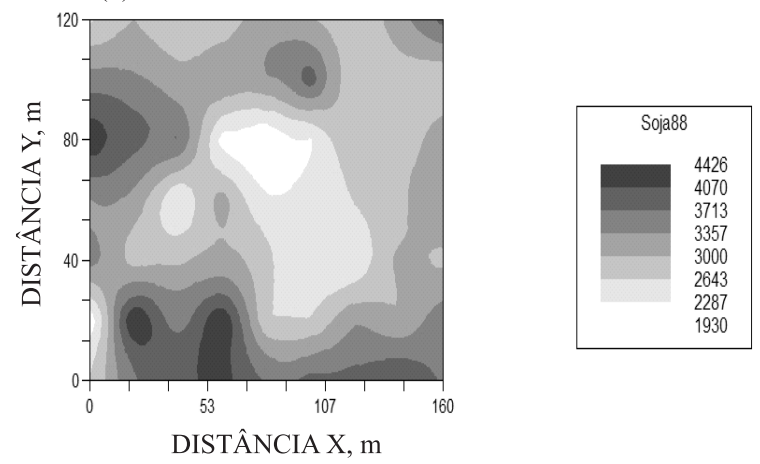

Figura 8. Semivariograma cruzado (a) e mapa de cokrigagem da produtividade de grãos de soja em função do teor de $\mathbf{P}$ foliar (b).

\section{CONCLUSÕES}

1. Houve dependência espacial para os teores foliares de alguns nutrientes e para a produtividade de grãos de soja passível de ser mapeada em uma área com cerca de 2 ha, adubada de maneira homogênea.

2. A dependência espacial não ocorreu de forma constante ao longo do tempo, o que deve ser considerado no estudo de cultivos sequenciais.
3. A dependência espacial da produtividade de soja aumentou entre os anos estudados.

4. Entre os nutrientes aplicados anualmente, via adubação, verificou-se a formação de um padrão de distribuição espacial, em 1986 e em 1988, especialmente para os teores de $\mathrm{P}$.

\section{LITERATURA CITADA}

BATAGLIA, O.C.; FURLANI, A.M.C.; TEIXEIRA, J.P.F.; FURLANI, P.R. \& GALLO, J.R. Métodos de análise química de plantas. Campinas, Instituto Agronômico de Campinas, 1983. 48p. (Boletim Técnico 78)

BERNARDI, A.C.C.; CARMO, C.A.F.S.; MACHADO, P.L.O.; SILVA, C.A.; VALENCIA, L.I.O. \& MEIRELLES, M.S. Variabilidade espacial de teores de nutrientes em folhas de soja como ferramenta para agricultura de precisão. Rio de Janeiro, Embrapa Solos, 2002. 5p. (Comunicado Técnico 17)

BORKET, C.M.; YORINORI, T.J.; CORRÊA-FERREIRA, B.S.; ALMEIDA, A.M.R.; FERREIRA, L.P. \& SFREDO, G.J. Seja o doutor da sua soja. Infor. Agron., 6:1-66, 1994.

CARVALHO, J.R.P.; SILVEIRA, P.M. \& VIEIRA, S.R. Geoestatística na determinação da variabilidade espacial de características químicas do solo sob diferentes preparos. Pesq. Agropec. Bras., 37:1151-1159, 2002.

CAVALCANTE, E.G.S.; ALVES, M.C.; SOUZA, Z.M. \& PEREIRA, G.T. Variabilidade espacial de atributos químicos do solo sob diferentes usos e manejos. R. Bras. Ci. Solo, 31:1329-1339, 2007.

DAVIS, J.C. Statistics and data analysis in geology. New York, John Wiley \& Sons, 1973. p.298-411.

EMPRESA BRASILEIRA DE PESQUISA AGROPECUÁRIA EMBRAPA. Centro Nacional de Pesquisa de Solos. Sistema brasileiro de classificação de solos. 2.ed. Rio de Janeiro, 2006. 306p.

ISAAKS, E.H. \& SRIVASTAVA, R.M. An introduction to applied geoestatistics. New York: Oxford University Press, 1989, $561 \mathrm{p}$.

MALAVOLTA, E. Manual de nutrição mineral de plantas. São Paulo, Agronômica Ceres, 2006. 638p.

MOLIN, J.P. Geração e interpretação de mapas de produtividade para agricultura de precisão. In: BORÉM, A., ed. Agricultura de precisão. Viçosa, MG, Universidade Federal de Viçosa, 2000. p.237-257.

MULLA, D. J. \& MCBRATNEY, A.B. Soil spatial variability. In: SUMNER, M. E., ed. Handbook of soil science. Boca Raton, CRC Press, 2000. p.A321-A352.

RESENDE, A.V.; KRAHL, L.L.; SHIRATSUCHI, L.S.; GOEDERT, W.J. \& DOWICH, I. Diagnóstico nutricional de uma lavoura de soja a partir de informações georreferenciadas. Planaltina, DF, Embrapa Cerrados, 2005. 30p. (Boletim de Pesquisa e Desenvolvimento, 145). 
SFREDO, G.J.; LANTMANN, A.F.; CAMPO, R.J. \& BORKET, C.M. Soja, nutrição mineral, adubação e calagem. Londrina, Embrapa-CNPSo, 1986. 51p. (Documentos Embrapa, 64)

SOUZA, L.S.; VIEIRA, S.R. \& COGO, N.P. Variabilidade dos teores de nutrientes na folha, entre plantas, em um pomar cítrico. R. Bras. Ci. Solo, 21:373-377, 1997.

SOUZA, Z.M.; BARBIERI, D.M.; MARQUES JÚNIOR, J.; PEREIRA, G.T. \& CAMPOS, M.C.C. Influência da variabilidade espacial de atributos químicos de um Latossolo na aplicação de insumos para cultura da canade-açúcar. Ci. Agrotec., 31:371-377, 2007.

GOLDEN SOFTWARE. SURFER for Windows. Release 7.0. Contouring and 3D surface mapping for scientist's engineers. User's guide. New York, Golden Software, 1999. 619p.
VIEIRA, S.R. Geoestatística em estudos de variabilidade espacial do solo. In: NOVAIS, R.F.; ALVAREZ V., V.H. \& SCHAEFER, G.R., eds. Tópicos em ciência do solo. Viçosa, MG, Sociedade Brasileira de Ciência do Solo, 2000. v.1. p.1-54.

VIEIRA, S.R.; MILLETE, J.; TOPP, G.C. \& REYNOLDS, W.D. Handbook for geostatistical analysis of variability in soil and climate data. In: ALVAREZ V., V.H.; SCHAEFER, C.E.G.R.; BARROS, N.F.; MELLO, J.W.V. \& COSTA, L.M., eds. Tópicos em ciência do solo. Viçosa, MG, Sociedade Brasileira de Ciência do Solo, 2002. v.2. p.1-45.

WARRICK, A.W. \& NIELSEN, D.R. Spatial variability of soil physical properties in the field. In: HILLEL, D., ed. Applications of soil physics. New York, Academic, 1980. p.319-344.

ZIMBACK, C.R.L. Análise especial de atributos quimicos de solos para fins de mapeamento da fertilidade. Botucatu, Universidade Estadual Paulista, 2001. 114p. (Tese de Livre Docência) 